NBER WORKING PAPER SERIES

\title{
MONETARY POLICIES FOR DEVELOPING COUNTRIES: \\ THE ROLE OF CORRUPTION
}

\author{
Haizhou Huang \\ Shang-Jin Wei \\ Working Paper 10093 \\ http://www.nber.org/papers/w10093
}

\section{NATIONAL BUREAU OF ECONOMIC RESEARCH 1050 Massachusetts Avenue Cambridge, MA 02138}

November 2003

We would like to thank Peter Clark, Ke-young Chu, Anne-Marie Gulde, Paul Masson, and Sunil Sharma for useful conversations and comments; participants at an IMF seminar and the 2002 LACEA conference for comments; and Hayden Smith for research assistance. The views expressed herein are those of the authors and not necessarily those of the National Bureau of Economic Research.

(C)2003 by Haizhou Huang and Shang-Jin Wei. All rights reserved. Short sections of text, not to exceed two paragraphs, may be quoted without explicit permission provided that full credit, including (C) notice, is given to the source. 
Monetary Policies for Developing Countries: The Role of Corruption

Haizhou Huang and Shang-Jin Wei

NBER Working Paper No. 10093

November 2003

JEL No. E52, E58, E61, E62, H50

\title{
ABSTRACT
}

This paper examines the role of corruption in the design of monetary policies for developing countries and obtains several interesting results. First, pegged exchange rates, currency boards, or dollarization, while often prescribed as a solution to the problem of a lack-of-credibility for developing countries, is typically not optimal in countries with serious corruption. Second, the optimal degree of conservatism for a Rogoff(1985)-type central banker is an inverse function of the corruption level. Third, either an optimally-designed inflation target or an optimal conservative central banker is preferable to an exchange rate peg, currency board, or dollarization.

\author{
Haizhou Huang \\ International Monetary Fund \\ Research Department \\ 19th Street, NW \\ Washington, DC 20433 \\ hhuang@imf.org \\ Shang-Jin Wei \\ International Monetary Fund \\ Research Department \\ 19th Street, NW \\ Washington, DC 20433 \\ and NBER \\ swei@imf.org
}




\section{INTRODUCTION}

Textbook discussions of monetary policies do not usually separate developing from developed countries. Are there important features about developing countries that might suggest that the optimal design of monetary policies should be different systematically between these groups of countries? In this paper, we study one particular feature that is prevalent in developing (and transition) economies, namely bureaucratic corruption. Obviously, developed countries are not immune to this problem, but it is far less prevalent than in many developing countries. Surprisingly, the consequence of corruption on the design of monetary policy has not been systematically examined. The main objective of this paper is to fill this void, and to demonstrate that the effect is not trivial.

As many developing countries lack credibility in their monetary policy, a subject heavily studied in the literature ${ }^{1}$ a conventional wisdom is that these developing countries should peg their currency to a major currency from a low-inflationary country, have a currency board, or dollarize. Our analysis in this paper will show, however, that when corruption is considered these policies are not necessarily appropriate.

Our theory combines useful ingredients from two different strands of the literature. The first strand is on the design of monetary policy, which is too voluminous to be referenced completely here, but recent seminal contributions include Kydland and Prescott (1977), Calvo (1978), Barro and Gordon (1983), Backus and Driffill (1985), Rogoff (1985), Barro (1986), Alesina and Tabellini (1987), Fischer (1995), Walsh (1995), and Svensson (1997). ${ }^{2}$ In this paper, we make use of a framework developed by Alesina and Tabellini (1987), where the government's objective function includes provision of public goods in addition to minimizing inflation and output fluctuations. ${ }^{3}$ This strand of literature acknowledges the importance of institutions in affecting inflation bias. However, a particular institutional feature that separates developing from developed countries is the severity of bureaucratic corruption. As far as we know, the literature on inflation targeting, on comparing discretionary versus rule-based monetary regimes, and on conservative central banker, has largely ignored this institutional feature.

The second strand studies the causes and consequences of corruption, which we use as a shorthand for weak public institutions generally. The seminal works include Rose-Ackerman (1975) and Shleifer and Vishny (1993). Bardhan (1997) provides a review. Empirically, Rauch and Evans (2000) and Van Rijckeghem and Weder (2001),

\footnotetext{
$1 \quad$ See, for example, Cukierman (1992) and Persson and Tabellini (1990).

2 See Berger and others (2001) for a recent survey of the literature.

3 For recent work on fiscal and monetary policy, see Benigno and Woodford (2003) and references cited there.
} 
among others, examined the determinants of corruption. Mauro (1995), Acemoglu, Robinson and Johnson (2001), Acemoglu, Johnson and Robinson (2002), Bai and Wei (2000), Du and Wei (2003), Fisman and Wei (2001), Wei (2000a, 2000b, 2001) investigated the consequences of weak public institutions including corruption for economic growth, capital controls, stock market volatility, tax evasion, and international capital flows. For the purpose of our paper, we model corruption as an erosion of a government's ability to collect revenue through formal tax channels. This may arise through the outright theft by tax officials, the hiding of taxable income by taxpayers, or practices whereby tax inspectors collude with taxpayers to reduce the latter's tax obligation in exchange for a bribe. As far as we know, these two strands of the literature have not been married before. In other words, none of the papers in the literature that we know of has examined the implications of corruption for the design of monetary policies.

Under an inflation targeting framework, we study how the socially optimal level of the inflation target is affected by corruption. We further examine the implications of corruption for the design of several other monetary frameworks, including a currency board, dollarization, and a Rogoff-type conservative central banker, and rank these monetary frameworks in terms of their social welfare. We also examine the authorities' incentive in fighting corruption and improving fiscal capacity from a political economy perspective.

Several interesting results emerge from our analysis. First, generally speaking, the optimal inflation target is higher for a high-corruption country than for a lowcorruption country. Hence, an inflation target of 1-4 percent, that is common among advanced industrialized countries and might be called "international best practice," is generally not something to be emulated by developing countries in our framework.

Second, pegged exchange rate, currency boards, or dollarization are often prescribed as ways to solve the lack of credibility problem. However, we show that these monetary regimes are typically not very credible themselves and are likely to fail (often associated with a currency crisis) in countries where corruption is rampant.

Third, a Rogoff-type conservative central banker is generally preferable to a mechanical inflation target of 1-4 percent and to all exchange-rate-based monetary arrangements. In equilibrium, the optimal degree of central bank conservatism is inversely related to the level of corruption in the economy. In the limit, when corruption makes collection of tax revenue infeasible, the optimal degree of conservatism is zero.

Fourth, we consider the political economy of corruption control. In particular, we ask whether forcing a government not to rely too much on the inflation tax through 
external pressure (e.g., conditionality in an IMF program) could induce it to fight corruption. The answer is probably not. One interesting result is that severe corruption can be a trap by itself. That is, when the initial level of corruption is sufficiently high, it would be difficult to induce the authorities to devote effort to fight it.

The paper proceeds as follows. In Section II, we set up the model and discuss the nature of the time inconsistency problem. In Section III, we analyze the nature of the monetary commitment and compare various popular frameworks that implement such a commitment, namely inflation targeting, a fixed exchange rate, a currency board, and dollarization. We find that the introduction of corruption helps to identify what undermines the desirability of these frameworks. In Section IV, we analyze the discretionary monetary regime and examine how a Rogoff-type conservative central banker can improve the outcome of the discretionary regime. In this section, we also compare the social welfare under a Rogoff-type conservative central banker with the three commitment frameworks and briefly discuss the issue of implementation. In Section V, we examine whether the authorities have incentive in fighting corruption and improving fiscal capacity from a political economy perspective. Section VI concludes.

\section{BASIC SETUP}

Our model utilizes a framework developed in Alesina and Tabellini (1987), which we think has not been sufficiently appreciated in the literature. The government's objective function includes public goods provision in addition to stabilizing inflation and output:

$$
V(\pi, \tau)=-\frac{1}{2}\left[\pi^{2}+y^{2}+(g-\bar{g})^{2}\right]
$$

In this objective function, the target levels for inflation and output are normalized to zero. In addition, the government aims to minimize the deviation of public goods provision from a nonnegative target $\bar{g} \cdot{ }^{4}$

4 The government's objective function can be expressed more generally as

$$
V(\pi, \tau)=-\frac{1}{2}\left[\pi^{2}+\alpha\left(y-y^{*}\right)^{2}+\beta(g-\bar{g})^{2}\right]
$$

where $\alpha>0$ and $\beta>0$ are the weights on output stability and public expenditure stability, respectively, and $y^{*}>0$ is the standard (high) target level of output that is the source of the inflation bias in the Barro-Gordon framework. Because the public goods provision at the $\bar{g}>0$ level already generates an inflation bias in our framework, without loss of generality we can focus our analysis on the simpler objective function given in equation (1), where $\alpha=\beta=1$, and $y^{*}=0$. We will also return to this issue in subsection IV.B. 
To generate an inflation bias under a discretionary regime in a Barro-Gordon (1983) model without public goods provision, one has to assume that a government's targeted output level is systematically above the long-run equilibrium. An interesting property of the Alesina-Tabellini reformulation is that the need to provide public goods $(\bar{g}>0)$ is enough to generate an inflation bias by itself. This is demonstrated below. For simplicity, we normalize the target output level to zero. A more general formulation à la Barro and Gordon (1983) merely complicates the algebra without yielding additional insights.

For simplicity, we consider a deterministic economy with no shocks to aggregate demand. A modified Lucas supply curve governs the relationship between aggregate output and government policies: unexpected monetary growth increases aggregate demand, and a discretionary tax rate reduces aggregate supply. ${ }^{5}$ Both monetary and fiscal policy choices are taken by the government. To be more precise, output is given by:

$$
y=\alpha\left(\pi-\pi^{e}-\tau\right), \alpha>0,
$$

where $y$ is the log of real output; $\pi$ and $\pi^{e}$ are, respectively, the actual and expected inflation rates; and $\tau$ is the tax rate on the total revenue of firms. ${ }^{6}$

Let $g$ denote the ratio of expenditure on public goods to output. To finance the public goods provision, the government has two sources of revenue: corporate tax $\tau$, and the inflation tax, $\pi$. A crucial assumption that we make is on the connection between the government's fiscal capacity and the level of corruption. More precisely, corruption is assumed to cause a leakage of the tax revenue: the greater the corruption, the greater the leakage. If the private sector pays a tax in the amount of $\tau$, only $\phi \tau$ accrues to the government, where $0 \leq \phi \leq 1$. $\phi$ can be thought of as a fiscal capacity index. If $\phi=1$, then there is no leakage of tax revenue to corruption. If $\phi=0$, then there is complete leakage and the government cannot collect any tax revenue.

\footnotetext{
5 Our main result carries out to more complex settings including random supply shocks, which we will elaborate on when comparing the inflation targeting framework with the currency board arrangement. This is, however, the simplest model we can think of that captures the interactions between the monetary and fiscal authorities and allows us to address corruption. For further discussion of this model and, in particular, of its micro-foundations, see Alesina and Tabellini (1987).

6 Equation (1) implicitly assumes that money demand is not affected by fiscal policy and, therefore, that fiscal policy is not subject to time inconsistencies. Otherwise, an independent central bank could not directly control inflation, since it would be jointly determined by the money supply and the tax rate.
} 
Following Alesina and Tabellini (1987), the government's budget constraint can be written as: ${ }^{7}$

$$
g=\phi \tau+\pi
$$

Note that when $\phi=1$, there is no corruption, and our model boils down to the set up in Alesina and Tabellini. Also, as in Alesina and Tabellini, our model abstracts from public debt. ${ }^{8}$

\section{COMMITMENT AND ITS IMPLEMENTATIONS}

\section{A. The Commitment Regime}

We consider an institutional setup in which monetary and fiscal authorities each control a single policy instrument (the inflation rate, $\pi$, by the central bank, and tax policy, $\tau$, by the fiscal authority), but share a common objective function defined by Equation (1). The two branches of the government solve a noncooperative game. The equilibrium inflation and tax rates are given by the Nash equilibrium of the game.

In this subsection, we focus on the case in which the central bank can credibly commit to a given inflation rate, i.e., $\pi=\pi^{e}$. It is easy to verify that, in this case, $y=-\alpha \tau$. The Nash equilibrium monetary and fiscal policies can be directly obtained from the first-order conditions associated with (1), where $y=-\alpha \tau:^{9}$

$$
\begin{gathered}
\pi^{C}(\tau)=\frac{1}{2}(\bar{g}-\phi \tau), \\
\tau^{C}(\pi)=\frac{\phi}{\alpha^{2}+\phi^{2}}(\bar{g}-\pi) .
\end{gathered}
$$

\footnotetext{
7 Equation (3) can be obtained from a two-step derivation as in Alesina and Tabellini (1987). First, the government budget constraint in nominal terms is: $G_{t}=\phi \tau_{t} P_{t} X_{t}+M_{t}-M_{t-1}$, where $G$ denotes public spending, $P$ price level, $X$ real output, and $M$ equilibrium money supply, respectively. Second, dividing both sides by nominal income $P_{t} X_{t}$, we have $g_{t}=\phi \tau_{t}+\left(M_{t}-M_{t-1}\right) / P_{t} X_{t}=\phi \tau_{t}+\pi_{t}$.

8 In our view, regular tax collection is more prone to leakage due to corruption than inflation tax collection, partly because the former involves many more layers of government bureaucracy. We focus on this case in this paper and notice that it is quite straightforward to extend the analysis to allow also for a leakage in inflation tax collection.

9 The second-order conditions associated with this problem (as well as those of the time-consistent problem below) are trivially satisfied since $V(\pi, \tau)$ is globally concave with respect to its arguments.
} 
Solving these two reaction functions together, we obtain the Nash equilibrium inflation and tax rates under commitment:

$$
\begin{aligned}
\pi^{C} & =\frac{\alpha^{2} \bar{g}}{2 \alpha^{2}+\phi^{2}}, \\
\tau^{C} & =\frac{\phi \bar{g}}{2 \alpha^{2}+\phi^{2}} .
\end{aligned}
$$

A number of observations can be made. First, if there is no need to provide public goods $(\bar{g}=0)$, then the equilibrium inflation (and tax) rate under a commitment regime would be zero, consistent with the result from Barro and Gordon. Second, the effect of corruption on inflation and taxes can be examined by taking the partial derivatives from (6) and (7),

$$
\begin{aligned}
\frac{\partial \pi^{C}}{\partial \phi} & =-\frac{2 \phi \alpha^{2} \bar{g}}{\left(2 \alpha^{2}+\phi^{2}\right)^{2}}<0 ; \\
\frac{\partial \tau^{C}}{\partial \phi} & =\frac{\left(2 \alpha^{2}-\phi^{2}\right) \bar{g}}{\left(2 \alpha^{2}+\phi^{2}\right)^{2}} .
\end{aligned}
$$

It is straightforward to see that the equilibrium inflation under a commitment regime goes up as corruption becomes more severe (or as $\phi$ goes down from one towards zero). The intuition is as follows: a rise in corruption essentially raises the shadow cost of raising revenue through regular tax channels vis-à-vis inflation tax. Consequently, a higher inflation is needed.

Third, the effect of corruption on the equilibrium tax rate falls into two ranges. For moderate corruption ( or $1 \geq \phi \geq \sqrt{2} \alpha$ ), the optimal response to a rise in corruption is to raise the tax rate. On the other hand, for severe corruption, $(\phi \leq \sqrt{2} \alpha)$, the optimal response to a rise in corruption is to reduce the tax rate. The nonmonotonicity of the effect can be understood as follows. When corruption is in the lower range, in response to a small increase in the rate of leakage in tax revenue, the government has to tax more to compensate for the lost revenue. On the other hand, if corruption is very severe, a given increment in tax revenue becomes too expensive to collect in terms of forgone output. As a result, for any increase in the rate of leakage, the optimal response is to shift the revenue collection from regular tax to inflation tax.

Using equations (6) and (7), we can also obtain the equilibrium values of output and public expenditure under commitment: $y^{C}=-\alpha \tau^{C}<0$ and $g^{C}=\phi \tau^{C}+\pi^{C}<\bar{g}$. More precisely, 


$$
\begin{gathered}
g^{C}=\phi \tau^{C}+\pi^{C}=\frac{\left(\alpha^{2}+\phi^{2}\right) \bar{g}}{2 \alpha^{2}+\phi^{2}}, \\
y^{C}=-\alpha \tau^{C}=-\frac{\alpha \phi \bar{g}}{2 \alpha^{2}+\phi^{2}} .
\end{gathered}
$$

Substituting $\pi^{C}, y^{C}$ and $g^{C}$ in (3), we have:

$$
V^{C}=-\frac{1}{2}\left[\left(\pi^{C}\right)^{2}+\left(y^{C}\right)^{2}+\left(g^{C}-\bar{g}\right)^{2}\right]=-\frac{1}{2} \frac{\alpha^{2} \bar{g}^{2}}{2 \alpha^{2}+\phi^{2}}=-\frac{1}{2} \bar{g} \pi^{C} .
$$

The level of social welfare is a negative function of the inflation rate. Since more corruption leads to a higher inflation rate, more corruption reduces social welfare.

To summarize, we have:

Proposition 1 Under the commitment regime, (1) the inflation rate goes up as corruption becomes more serious; (2) the tax rate goes up (or down) with corruption if corruption is moderate (or severe); and (3) social welfare decreases as corruption increases.

\section{B. Inflation Targeting}

Four popular frameworks have been developed to implement the commitment regime. They are inflation targeting, a fixed exchange rate, a currency board arrangement, and dollarization. We will analyze and compare the desirability of these frameworks based on the insights from this model.

Inflation targeting is a monetary arrangement in which the central bank announces (or is asked to follow) a target level (or range) for the inflation rate. ${ }^{10}$ In principle, inflation targeting can be viewed as an institutional commitment to achieve the desirable outcome $\left(\pi^{C}, \tau^{C}\right.$ and $\left.g^{C}\right)$ instead of $\left(\pi^{D}, \tau^{D}\right.$ and $\left.g^{D}\right)$.

There are quite a few developed countries that have adopted some version of inflation targeting. They include Australia, Canada, New Zealand, Norway, Sweden, the United Kingdom, and Finland and Spain before the ECB became operative. In practice, these countries target their inflation rates to a relatively narrow range, typically a 1-4 percent range. The fact that the inflation target is a range rather than a point is explained by the existence of unanticipated shocks, such as a temporary disturbance to

$1 \overline{\text { See Bernanke and others (1999) }}$ for recent international experience of inflation targeting. 
money demand that the central bank ought to respond to. For simplicity, shocks are assumed away in this paper. It is sometimes thought that a similar type of inflation target would benefit developing countries as well. For example, the IMF has advised several transition and emerging market economies to adopt inflation targeting with a similarly narrow range.

The empirical evidence, however, by and large shows that inflation targeting has been less successful in developing economies than in developed countries. In fact, many developing countries are quite reluctant to adopt this new monetary framework, even though lack of credibility is a clear concern for them. We believe that the higher degree of corruption in developing countries provides one important reason. ${ }^{11}$

It may be useful to make a distinction between a mechanical inflation target of 1-4 percent and an optimally chosen range for such a target. A mechanical inflation targeting is a framework that advocates developing countries to do what developed countries have been doing, namely to target a low inflation rate like 3 percent (or a narrow range in that neighborhood). Optimal inflation targeting is an arrangement that is the optimal solution under the commitment regime. More precisely, the optimal mix of monetary and fiscal policies should be (6) and (7) respectively, i.e.,

$$
\begin{aligned}
\pi^{C} & =\frac{\alpha^{2} \bar{g}}{2 \alpha^{2}+\phi^{2}}, \\
\tau^{C} & =\frac{\phi \bar{g}}{2 \alpha^{2}+\phi^{2}}
\end{aligned}
$$

In other words, the optimal inflation target for the central bank is:

$$
\pi^{I T}=\pi^{C}=\frac{\alpha^{2} \bar{g}}{2 \alpha^{2}+\phi^{2}}
$$

An immediate implication is that optimal inflation targeting should be a function of the corruption level. The higher the corruption level (or the greater the slope of the Phillip's curve or the higher the target level of public goods provision), the higher the optimal level of the inflation target should be.

For the purpose of illustration, consider a comparison between a low-corruption country, $l$, (e.g., Sweden) and a high-corruption country, h, (e.g., Russia). Suppose that

$11 \quad$ Masson, Savastano, and Sharma (1997) and Eichengreen, Masson, Savastano, and Sharma (1999) stated that a monetary authority "free of fiscal dominance" is a precondition for the success of an inflation targeting regime. Our model can be viewed as a formalization of their argument. In our view, the existence of high corruption means that the optimal range for an inflation target is higher. 
corruption is the only thing that is different between these two economies $\phi_{l}=1$ and $\phi_{h}=1 / 4, \alpha_{l}=\alpha_{h}=\alpha=1 / 4$, and $\bar{g}_{l}=\bar{g}_{h}$. In this case, it is easy to verify that

$$
\pi_{h}^{C}=\frac{2 \alpha^{2}+\phi_{l}^{2}}{2 \alpha^{2}+\phi_{h}^{2}} \pi_{l}^{C}=6 \pi_{l}^{C}
$$

In this case, the optimal inflation target for Russia should be six times the level of what is optimal for Sweden. In other words, if a 3 percent inflation target is optimal for Sweden, then the optimal level of the inflation target for Russia should be 18 percent rather than 3 percent. This admittedly artificial example illustrates the significance of corruption for inflation targeting and shows that a high-corruption country should target a higher inflation than a low-corruption country. Further, such an action raises social welfare compared to a regime of mechanical inflation targeting.

\section{Currency Board and Fixed Exchange Rate}

A fixed exchange rate regime, by definition, fixes the rate of exchange between the domestic currency and an anchor currency. A currency board arrangement is a monetary framework whereby domestic money is rigidly pegged to a foreign currency and domestic high-powered money is completely backed up by foreign exchange reserves in hard currencies (or their equivalents). ${ }^{12}$ By construction, under a fixed exchange rate or currency board arrangement, there is an implied inflation target which is the inflation rate in the anchor country's inflation rate. Suppose $\widehat{\pi}$ denotes the inflation rate in the anchor country. Generally speaking, the anchor currency is that of a low-corruption country. We have already seen from the discussion on inflation targeting that the optimal level of inflation for a high-corruption country is higher than that for a low-corruption one. Therefore, there is a welfare loss associated with a fixed exchange rate or currency board arrangement for a high-corruption country. To put it differently, our discussion suggests that for a high-corruption country, there is tension under a fixed rate or currency board arrangement between the implied inflation target (i.e., a relatively low level) and the inflation rate that the country finds optimal to pursue (i.e., a relatively high level). The tension can be relieved if the country can effectively reduce corruption or adopt other compensating policies or institutions.

To see this in more precise terms, we can work out the welfare loss for a high-corruption country under a fixed rate or currency board arrangement. Given the monetary arrangement, the authority is left with only one independent instrument, tax

12 See Ghosh, Gulde, and Wolf (2000, 2003) for insightful discussions on currency board and its problems. 
rate $\tau$. Thus the fiscal policy can be directly obtained from the first-order condition of (3) with respect to $\tau$. This yields:

$$
\tau^{C B}(\pi)=\frac{\phi}{\alpha^{2}+\phi^{2}}(\bar{g}-\widehat{\pi}),
$$

Assuming that the anchor country can effectively implement an inflation target that is optimal for its economy, then

$$
\pi_{j}^{C}=\frac{\alpha_{j}^{2} \bar{g}_{j}}{2 \alpha_{j}^{2}+\phi_{j}^{2}}
$$

But $\pi_{j}^{C}$ can also be mapped into the $(\alpha, \bar{g})$ space such that

$$
\pi^{C B}=\frac{\alpha^{2} \bar{g}}{2 \alpha^{2}+\widehat{\phi}_{j}^{2}}=\frac{\alpha_{j}^{2} \bar{g}_{j}}{2 \alpha_{j}^{2}+\phi_{j}^{2}}=\pi_{j}^{C}
$$

Thus,

$$
\tau^{C B}=\frac{\phi\left(\alpha^{2}+\widehat{\phi}_{j}^{2}\right) \bar{g}}{\left(\alpha^{2}+\phi^{2}\right)\left(2 \alpha^{2}+\widehat{\phi}_{j}^{2}\right)} .
$$

The difference between the inflation levels is

$$
\pi^{C}-\pi^{C B}=\frac{\widehat{\phi}_{j}^{2}-\phi^{2}}{2 \alpha^{2}+\widehat{\phi}_{j}^{2}} \pi^{C} .
$$

Once again, the more serious the corruption in the country that adopts a currency board arrangement (a lower $\phi$ ), the higher the difference between the levels of inflation under a currency board arrangement and under a commitment regime.

Moreover, the differences between the tax rate under currency board and under commitment is

$$
\tau^{C B}-\tau^{C}=\frac{\left(\widehat{\phi}_{j}^{2}-\phi^{2}\right) \alpha^{2} \tau^{C}}{\left(\alpha^{2}+\phi^{2}\right)\left(2 \alpha^{2}+\widehat{\phi}_{j}^{2}\right)}
$$


And the level of social welfare under a currency board is

$$
V^{C B}=-\frac{\bar{g} \pi^{C}}{2} \frac{\left[\alpha^{2}\left(\alpha^{2}+\phi^{2}\right)+\left(\alpha^{2}+\widehat{\phi}_{j}^{2}\right)^{2}\right]\left(2 \alpha^{2}+\phi^{2}\right)}{\left(\alpha^{2}+\phi^{2}\right)\left(2 \alpha^{2}+\widehat{\phi}_{j}^{2}\right)^{2}}<-\frac{1}{2} \bar{g} \pi^{C}=V^{C} .
$$

Under the assumption that $\widehat{\phi}_{j}>\phi$, and thus $\pi^{C B}<\pi^{C}$ and $\tau^{C B}>\tau^{C}$. In other words, relative to an optimal commitment regime, a currency board arrangement implies too low an inflation rate but too high a tax rate.

So far, we have not used the word "credibility" in our discussion. Of course, introducing credibility is considered one major motive for countries to adopt a fixed rate regime or a currency board. Our discussion in this subsection suggests corruption as a possible source of lack of credibility. A fixed rate regime or a currency board is more difficult to sustain in a high-corruption country because the inflation rate implied by the exchange rate regime is too low from the viewpoint of the country.

In the previous discussion, we assumed away stochastic shocks to the aggregate Phillips curve. With these shocks, a fixed exchange rate, a currency board arrangement, and mechanical inflation targeting (that targets to the level of inflation in the anchor country) are equivalent. However, we note parenthetically that if shocks are introduced, an inflation targeting framework can dominate a fixed-rate or currency board arrangement as it allows for the flexibility to respond to shocks that are specific to the domestic economy.

\section{Dollarization}

Dollarization, or more generally, the adoption of a foreign currency, is a monetary arrangement that involves an even stronger commitment to low inflation -assuming the anchor country has low inflation- than a currency board arrangement. Unlike a currency board arrangement, the national currency disappears completely under dollarization. ${ }^{13}$ The commitment is stronger because the cost to the government of reversing such an arrangement is higher. If the anchor country is the same for a currency board and for dollarization (e.g., the United States), the inflation rates of the two regimes are obviously the same. However, the government in a dollarization regime has to forgo seigniorage revenue associated with the issue of domestic money. Hence,

13 See Fischer (1982), among others, for an analysis of seigniorage as a rationale for a national money. 
the social welfare is lower under a dollarization regime than under a currency board arrangement.

To demonstrate the social loss more precisely, we start by noting that the loss of the inflation tax implies the following (3)

$$
g=\phi \tau
$$

As in the currency board arrangement, under dollarization the authority is left with only one independent instrument, tax rate $\tau$. Using (15) in (3) and then taking the first-order condition of (1) with respect to $\tau$ yields:

$$
\tau^{D O}(\pi)=\frac{\phi \bar{g}}{\alpha^{2}+\phi^{2}}
$$

Denoting $\pi^{D O}$ as the inflation rate of country $j$ under rational expectations, where $j$ can be the United States or another country whose currency replaces the domestic currency in circulation. Mapping $\pi_{j}^{C}$ into the $\left(\alpha, \bar{g}_{j}\right)$ space, we have

$$
\pi^{D O}=\frac{\alpha^{2} \bar{g}}{2 \alpha^{2}+\widehat{\phi}_{j}^{2}}=\frac{\alpha_{j}^{2} \bar{g}_{j}}{2 \alpha_{j}^{2}+\phi_{j}^{2}}=\pi_{j}^{C}
$$

Once again, we should expect that $\pi^{D O}<\pi^{C}$. That is, the inflation level under dollarization is generally below that under an optimal commitment regime. Obviously,

$$
\pi^{D O}=\pi^{C B}
$$

Similar to a currency board arrangement, the more serious is domestic corruption (a lower $\phi$ ), the higher is the difference between the level of inflation under dollarization and that under a commitment regime.

Moreover,

$$
\tau^{D O}-\tau^{C}=\frac{\phi \alpha^{2} \bar{g}}{\left(\alpha^{2}+\phi^{2}\right)\left(2 \alpha^{2}+\phi^{2}\right)}>0
$$




$$
\tau^{D O}-\tau^{C B}=\frac{\phi \alpha^{2} \bar{g}}{\left(\alpha^{2}+\phi^{2}\right)\left(2 \alpha^{2}+\widehat{\phi}_{j}^{2}\right)}>0
$$

Evaluating $V\left(\pi^{D O}, \tau^{D O}\right)$, we get

$$
V^{D O}=-\frac{\bar{g} \pi^{C}}{2}\left[\frac{\alpha^{2}\left(2 \alpha^{2}+\phi^{2}\right)}{\left(2 \alpha^{2}+\widehat{\phi}_{j}^{2}\right)^{2}}+\frac{\phi^{2}\left(2 \alpha^{2}+\phi^{2}\right)}{\alpha^{2}\left(\alpha^{2}+\phi^{2}\right)}\right]<-\frac{1}{2} \bar{g} \pi^{C}=V^{C} .
$$

Moreover,

$$
\frac{V^{D O}}{V^{C B}}=\frac{\alpha^{4}\left(\alpha^{2}+\phi^{2}\right)+\phi^{2}\left(2 \alpha^{2}+\widehat{\phi}_{j}^{2}\right)^{2}}{\alpha^{4}\left(\alpha^{2}+\phi^{2}\right)+\alpha^{2}\left(\alpha^{2}+\widehat{\phi}^{2}\right)^{2}}>1
$$

if $\phi \geq \alpha$, which is a weaker condition than $\phi \geq \sqrt{2} \alpha$, and thus will likely hold unless corruption is very serious. If $\phi<\alpha$, then $V^{D O}<V^{C B}<0$.

At this point, we can rank the various monetary frameworks.

Proposition 2 Generally speaking, the optimal commitment regime dominates a mechanical inflation targeting regime, which (weakly) dominates a fixed rate or currency board arrangement, which in turn dominates a dollarization regime.

\section{DISCRETION AND CONSERVATIVE CENTRAL BANKER}

\section{A. A Conventional Discretionary Regime}

If the central bank cannot precommit, the inflation rate (and correspondingly the tax rate) derived for a commitment regime would not be time consistent. As is well known in the literature, if the expected inflation were at the commitment level $\left(\pi^{e}=\pi^{C}\right)$, the central bank would always find it optimal to raise inflation unexpectedly. Hence, such inflation expectations would not be rational. The time-consistent policy mix, $\left(\pi^{D}, \tau^{D}\right)$, is the Nash equilibrium solution to the noncoordinated game played by the central bank and fiscal authority, who take the expected inflation rate as given. 
The solution is characterized by the first-order conditions associated with (1), where, in addition, we require that the expected inflation rate equals its equilibrium value. More precisely, $\left(\pi^{D}, \tau^{D}\right)$ solves the following pair of equations:

$$
\begin{gathered}
\pi^{D}(\tau)=\frac{1}{2}(\bar{g}-\phi \tau)+\frac{\alpha^{2}}{2} \tau \\
\tau^{D}(\pi)=\frac{\phi}{\alpha^{2}+\phi^{2}}(\bar{g}-\pi) .
\end{gathered}
$$

Solving (19) and (20) for $\pi^{D}$ and $\tau^{D}$, we have the Nash equilibrium policy mix:

$$
\begin{aligned}
\pi^{D} & =\frac{(1+\phi) \alpha^{2} \bar{g}}{(2+\phi) \alpha^{2}+\phi^{2}} \\
\tau^{D} & =\frac{\phi \bar{g}}{(2+\phi) \alpha^{2}+\phi^{2}}
\end{aligned}
$$

We can examine how monetary and fiscal policies would optimally respond to a rise in the corruption level and compare it with the case when the central bank is able to commit. In contrast to the commitment regime, the optimal response of both monetary and fiscal policies to a rise in corruption depends on how severe corruption is. More precisely, from (21) and (22), we can show that

$$
\begin{aligned}
\frac{\partial \pi^{D}}{\partial \phi} & =\frac{\left[\alpha^{2}+1-(1+\phi)^{2}\right] \alpha^{2} \bar{g}}{\left[(2+\phi) \alpha^{2}+\phi^{2}\right]^{2}} \\
\frac{\partial \tau^{D}}{\partial \phi} & =\frac{\left(2 \alpha^{2}-\phi^{2}\right) \bar{g}}{\left[(2+\phi) \alpha^{2}+\phi^{2}\right]^{2}}
\end{aligned}
$$

If corruption is relatively modest (e.g., $\phi \geq \sqrt{\alpha^{2}+1}-1$ ), then the optimal response to a rise in corruption is to raise the inflation rate $\left(\partial \pi^{D} / \partial \phi<0\right)$. On the other hand, if the corruption level is already serious $\left(\phi \leq \sqrt{\alpha^{2}+1}-1\right)$, then the opposite response (lowering the inflation tax) to a rise in corruption would be optimal. The optimal response of the fiscal policy, $\tau^{D}$, also has a similar nonmonotonicity. For moderate corruption $(\sqrt{2} \alpha<\phi)$, an optimal response to a rise in corruption is to raise the tax rate. But at a more serious level of corruption $(\sqrt{2} \alpha \geq \phi)$, the optimal response would be to lower the tax rate.

This makes an interesting comparison with the commitment case. For example, starting at a high level of corruption (e.g., $\phi \leq \sqrt{\alpha^{2}+1}-1$ ), the optimal monetary policy response to a rise in corruption is to lower the inflation rate under a discretionary 
regime, but to raise the inflation rate under a commitment regime. A natural question to ask is whether the "excessive" level of inflation under a discretionary regime relative to a commitment regime could disappear at a very high level of corruption. A related question is whether the welfare ordering of a commitment versus a discretionary regime could be switched at a high level of corruption.

To see the answer to the first question, we can work out the difference between the inflation rate (and the tax rate) between the two regimes:

$$
\begin{aligned}
\pi^{D}-\pi^{C} & =\frac{\alpha^{2} \phi\left(\alpha^{2}+\phi^{2}\right) \bar{g}}{\left(2 \alpha^{2}+\phi^{2}\right)\left[(2+\phi) \alpha^{2}+\phi^{2}\right]} \\
\tau^{D}-\tau^{C} & =-\frac{\alpha^{2} \phi^{2} \bar{g}}{\left(2 \alpha^{2}+\phi^{2}\right)\left[(2+\phi) \alpha^{2}+\phi^{2}\right]}
\end{aligned}
$$

It can be seen that, as long as $\phi>0$, the inflation level under discretion is always higher than under commitment (whereas the tax rate under discretion is always lower than under commitment). In the extreme case in which corruption makes tax collection infeasible $(\phi=0)$, the differences in the monetary and fiscal policies under the two regimes $\left(\pi^{D}-\pi^{C}\right.$ and $\tau^{D}-\tau^{C}$, respectively) tend to disappear.

To answer the second question, it would be useful to first work out the amount of public goods to be provided and the level of output. Using $\pi^{D}$ and $\tau^{D}$ in $g^{D}=\phi \tau^{D}+\pi^{D}$, we have

$$
g^{D}=\frac{\left[(1+\phi) \alpha^{2}+\phi^{2}\right] \bar{g}}{(2+\phi) \alpha^{2}+\phi^{2}} .
$$

Using $\tau^{D}$ in $y^{D}=-\alpha \tau^{D}$ under the discretionary regime, we have

$$
y^{D}=-\alpha \tau^{D}=-\frac{\alpha \phi \bar{g}}{(2+\phi) \alpha^{2}+\phi^{2}} .
$$

Therefore, $V\left(\pi^{D}, \tau^{D}\right)$ becomes

$$
V^{D}=-\frac{1}{2} \frac{\alpha^{2}\left[\left(2+2 \phi+\phi^{2}\right) \alpha^{2}+\phi^{2}\right] \bar{g}^{2}}{\left[(2+\phi) \alpha^{2}+\phi^{2}\right]^{2}} .
$$


Comparing $V^{D}$ with $V^{C}$, we have

$$
\frac{V^{D}}{V^{C}} \geq 1
$$

where the equality sign holds when $\phi=0$.

To summarize, we have:

Proposition 3 The optimal commitment regime generates a higher social welfare than the discretionary regime.

Only in the extreme case when corruption completely destroys the tax collection system $(\phi=0)$ would the difference between the two regimes disappear.

\section{B. A Rogoff-type Conservative Central Banker}

The discussion in Section IV.A suggests that the optimal commitment regime strictly dominates the discretionary regime for every level of corruption except for the extreme case in which corruption renders the regular tax collection completely infeasible. This is a relatively modest generalization of the result in Kydland and Prescott (1978) and Barro and Gordon (1983).

If, for whatever reason, a commitment regime of any sort is not available, then, as proved by Rogoff (1985), delegating the monetary policy to a more conservative central banker (still with discretion) can improve upon the social welfare relative to a straightforward discretionary regime discussed in Section IV.A. Here, "more conservative" means the weight in the loss function on inflation placed by the central banker is higher than by the social planner.

In this section, we examine whether and how the optimal degree of central banker conservatism is affected by the presence of corruption. As a by-product, we also examine how the inclusion of public goods provision in the social welfare function may modify our understanding of the role of a conservative central banker.

Consider a modified central banker's problem. Let $S$ denote the weight on the inflation rate placed by the central banker. The central banker's objective function is given by, 


$$
V^{C C}(\pi, \tau)=-\frac{1}{2}\left[S \pi^{2}+y^{2}+(g-\bar{g})^{2}\right]
$$

If the central banker cares about inflation as much as the social planner, then $S=1$. If the central banker is more conservative than the social planner, then $S \geq 1$.

The central banker and the fiscal authority still play a noncooperative Nash game. The time-consistent policy mix in this case, labeled as $\left(\pi^{C C}, \tau^{C C}\right)$, is characterized by the first-order conditions associated with (26), where, in addition, we require that the expected inflation rate equals its equilibrium value. Thus, $\left(\pi^{C C}, \tau^{C C}\right)$ solves the following pair of equations:

$$
\begin{gathered}
\pi^{C C}(\tau)=\frac{1}{1+S}(\bar{g}-\phi \tau)+\frac{\alpha^{2}}{1+S} \tau \\
\tau^{C C}(\pi)=\frac{\phi}{\alpha^{2}+\phi^{2}}(\bar{g}-\pi) .
\end{gathered}
$$

Solving (27) and (28) for $\pi^{C C}$ and $\tau^{C C}$, we have:

$$
\begin{aligned}
\pi^{C C} & =\frac{(1+\phi) \alpha^{2} \bar{g}}{(1+S+\phi) \alpha^{2}+S \phi^{2}}, \\
\tau^{C C} & =\frac{S \phi \bar{g}}{(1+S+\phi) \alpha^{2}+S \phi^{2}}
\end{aligned}
$$

Obviously, at $S=1$, the regime of a conservative central banker collapses to the discretionary regime without a conservative central banker. When $S>1$, we can show easily that

$$
\left\{\begin{array}{l}
\pi^{C C}<\pi^{D} \\
\tau^{C C}>\tau^{D} .
\end{array}\right.
$$

In fact, $\partial \pi^{C C} / \partial S<0$ and $\partial \tau^{C C} / \partial S>0$. Therefore, the more conservative is the central banker, the lower the equilibrium inflation rate is, but the higher the tax rate becomes.

The effect of a rise in corruption on the inflation rate (or tax rate) is nonmonotonic. From (29) and (30), it is clear that 


$$
\begin{aligned}
\frac{\partial \pi^{C C}}{\partial \phi} & =\frac{S\left[\alpha^{2}+1-(1+\phi)^{2}\right] \alpha^{2} \bar{g}}{\left[(1+S+\phi) \alpha^{2}+S \phi^{2}\right]^{2}} \\
\frac{\partial \tau^{C C}}{\partial \phi} & =\frac{S\left[(1+S) \alpha^{2}-S \phi^{2}\right) \bar{g}}{\left[(2+\phi) \alpha^{2}+\phi^{2}\right]^{2}} .
\end{aligned}
$$

As in a conventional discretionary regime, $\partial \pi^{C C} / \partial \phi>0$ if and only if $\phi \leq \sqrt{\alpha^{2}+1}-1$. That is, when corruption is very serious, the optimal response to a rise in corruption is to lower inflation. On the other hand, if $\phi>\sqrt{\alpha^{2}+1}-1$, i.e., when corruption is relatively modest, then $\partial \pi^{C C} / \partial \phi<0$, which means that an optimal response to a rise in corruption is to raise inflation.

There is a similar asymmetry for the response of fiscal policy. When corruption is sufficiently serious, i.e., $\phi \leq \alpha \sqrt{1+S} / \sqrt{S}$, the optimal response to a rise in corruption is to lower the tax, $\partial \tau^{C C} / \partial \phi \geq 0$. On the other hand, when corruption is relatively modest, i.e., $\phi>\alpha \sqrt{1+S} / \sqrt{S}$, then the opposite adjustment in the fiscal policy is appropriate, since $\partial \tau^{C C} / \partial \phi<0$.

Using $\pi^{C C}$ and $\tau^{C C}$ in $g^{C C}=\phi \tau^{C C}+\pi^{C C}$, we can compute the level of public goods provision:

$$
g^{C C}=\frac{\left[(1+\phi) \alpha^{2}+S \phi^{2}\right] \bar{g}}{(1+S+\phi) \alpha^{2}+S \phi^{2}} .
$$

Using $\tau^{C C}$ in $y^{C C}=-\alpha \tau^{C C}$ under a conservative central banker, we have

$$
y^{C C}=-\alpha \tau^{C C}=-\frac{S \alpha \phi \bar{g}}{(1+S+\phi) \alpha^{2}+S \phi^{2}} .
$$

Accordingly, the level of social welfare (26) becomes

$$
V^{C C}\left(\pi^{C C}, \tau^{C C}\right)=-\frac{1}{2} \frac{\alpha^{2}\left[\left[S^{2}+(1+\phi)^{2}\right] \alpha^{2}+S^{2} \phi^{2}\right] \bar{g}^{2}}{\left[(1+S+\phi) \alpha^{2}+S \phi^{2}\right]^{2}} .
$$

Suppose the social planner can choose any value of $S$, then what is the optimal degree of conservatism of the central banker that would maximize the social welfare? 
To answer this, we maximize the social welfare function described by (33) with respect to $S$. The first-order condition leads to ${ }^{14}$

Proposition $4 S^{*}=1+\phi$.

Let us measure the degree of conservatism of the central banker by the excess weight she places on the inflation term relative to the social planner, i.e., conservatism $=S-1$. The above equation suggests that the optimal degree of conservatism is given by $S^{*}-1=\phi$. A number of observations can be made. First, for $0<\phi \leq 1$, a central banker that is more conservative than the social planner should be appointed to improve upon the social welfare under a discretionary regime. Second, the optimal degree of conservatism depends on the degree of corruption in the economy. The greater the level of corruption (i.e., a lower value of $\phi$ ), the less conservative the central banker should be. Third, in the extreme case in which corruption prevents the working of the tax system completely (i.e., when $\phi=0$ ), the optimal degree of conservatism is zero. That is, the social planner would choose a central banker who has the same preference as herself.

When the central banker is optimally chosen (i.e., $S^{*}=1+\phi$ ), we can compute the level of inflation, taxes, and social welfare. It can easily be verified that

$$
\begin{aligned}
\pi^{C C} & =\frac{\alpha^{2} \bar{g}}{2 \alpha^{2}+\phi^{2}}=\pi^{C}, \\
\tau^{C C} & =\frac{\phi \bar{g}}{2 \alpha^{2}+\phi^{2}}=\tau^{C}, \\
V^{C C} & =-\frac{1}{2} \frac{\alpha^{2} \bar{g}^{2}}{2 \alpha^{2}+\phi^{2}}=V^{C} .
\end{aligned}
$$

Proposition 5 When the conservatism of the central banker is optimally determined, this (modified) discretionary regime restores the first-best solution under commitment.

This proposition is somewhat surprising and worth some further elaboration. There are a number of differences between our framework and that of the original Rogoff framework. First, in Rogoff (1985), the social planner is only concerned with inflation and output stabilization. In contrast, we have added public goods provision as part of the objective function. Although a more conservative central banker can lower inflation further, it would not be optimal to do that given the increasing costs of collecting taxes. Second, we do not have stochastic shocks to the aggregate supply/demand. Third, we

14 It is easy to verify that (33) is indeed convex in $S$. 
do not have the equivalent of the labor market distortion that causes the social planner to attempt to stabilize output at a level above its natural rate.

It is clear that the welfare under a Rogoff-style conservative central banker dominates that in a currency board arrangement or dollarization. One may think that installing a conservative central banker requires fewer technical preconditions than implementing an inflation targeting framework due to the principle of contract implementation (Maskin and Moore (1999), Moore and Repullo (1988 and 1990)). ${ }^{15}$ If that is true, the conservative central banker may also be better than an inflation targeting framework, though it is beyond the scope of this paper to have a full discussion on this issue.

In the absence of public goods provision (and hence fiscal policy), the Walsh (1995) contract implements the commitment solution under a discretionary regime. However, once fiscal policy is introduced, strategic manipulation by the fiscal authority could make the Walsh contract suboptimal (Huang and Padilla (2002)). ${ }^{16}$ As a result, the discretionary tax can be too high while the inflation rate may be too low. By this logic, the Rogoff-type conservative central banker arrangement may outperform the Walsh-type incentive contract.

\section{FIGHTING CORRUPTION AND IMPROVING FISCAL CAPACITY}

So far we have treated fiscal capacity, $\phi$, as exogenously given. Efforts in fighting corruption and improving fiscal capacity should increase the value of $\phi$. In this section we endogenize corruption and ask when a government would be willing to undertake anti-corruption reforms.

To start with, we observe that a government's effort to fight corruption and improve fiscal capacity is likely to come with a cost. The cost could be in the form of a loss of economic rents that officials enjoy, or a stiffened resistance from powerful special interest groups that have been benefiting from corruption and lost tax revenue. To capture this observation, we assume that

$$
\phi \quad=\phi_{0}+f
$$

where $f \in\left[0,\left(1-\phi_{0}\right)\right]$ denotes the level of effort by authorities, $\phi_{0}$ is the initial value of $\phi$ before any efforts have been devoted. We assume further that the authorities

15 See Moore (1992) for an excellent survey of this literature.

16 Their paper, nevertheless, does not study the effects of corruption. 
otherwise share the preference of the social planner except that they also have to bear the cost of fighting corruption, which is proportional to their effort,

$$
C=\theta f
$$

where $\theta>0$ is the unit cost coefficient.

With this simple setup, the equilibrium effort level, and thus the equilibrium value of $\phi$ can be solved in two steps in a principal-agent framework. Because an optimally chosen (Rogoff-type) central banker can implement the commitment regime under discretion, there is no loss of generality by focusing on the commitment case alone. The policy game is the same as before, except that the authorities, foreseeing a commitment monetary regime, need to choose their level of anti-corruption effort first.

Recall that under the commitment regime, the value of the loss function, i.e., $(10)$, is

$$
V^{C}=-\frac{1}{2} \frac{\alpha^{2} \bar{g}^{2}}{2 \alpha^{2}+\phi^{2}}
$$

Since the authorities share the preference of the social planner, their loss inclusive of the costs of efforts devoted to fighting corruption is

$$
V_{A}^{C}(f)=-\frac{1}{2} \frac{\alpha^{2} \bar{g}^{2}}{2 \alpha^{2}+\left(\phi_{0}+f\right)^{2}}-\theta f .
$$

Taking first derivative of (34) with respect to $f$, one gets

$$
\frac{\alpha^{2} \bar{g}^{2}\left(\phi_{0}+f\right)}{\left[2 \alpha^{2}+\left(\phi_{0}+f\right)^{2}\right]^{2}}-\theta=0
$$

Examining this first-order condition (35), we have the following proposition.

Proposition 6 For

$$
\frac{\alpha^{2} \bar{g}^{2}}{\left(2 \alpha^{2}+1\right)^{2}} \equiv \underline{\theta}<\theta<\bar{\theta} \equiv \frac{\alpha^{2} \bar{g}^{2} \phi_{0}}{\left(2 \alpha^{2}+\phi_{0}^{2}\right)^{2}}
$$


an interior optimal solution $0<f^{*}<1-\phi_{0}$ exists.

The equilibrium inflation and tax rates are

$$
\begin{gathered}
\pi_{A}^{C}=\frac{\alpha^{2} \bar{g}}{2 \alpha^{2}+\left(\phi_{0}+f^{*}\right)^{2}}<\pi^{C}, \\
\tau_{A}^{C}=\frac{\left(\phi_{0}+f^{*}\right) \bar{g}}{2 \alpha^{2}+\left(\phi_{0}+f^{*}\right)^{2}}=\left\{\begin{array}{l}
\leq 0, \text { if } \sqrt{2} \alpha \leq \phi_{0}+f^{*} ; \\
>0, \text { if } \sqrt{2} \alpha>\phi_{0}+f^{*} .
\end{array}\right.
\end{gathered}
$$

Further examining the first-order condition (35), we have the following corollary, which suggests that the cost coefficient, $\theta$, is a key parameter that affects the authorities' incentive to fight corruption and improve fiscal capacity.

Corollary 1 If $\theta \geq \bar{\theta}$, then the authorities would have no incentive to devote any efforts to fight corruption; If $\theta<\underline{\theta}$, however, the authorities would have incentive to devote full efforts to fight corruption and improve fiscal capacity so that $\phi=1$.

We note

$$
\lim _{\phi_{0} \rightarrow 0} \bar{\theta}=0
$$

In other words, when the initial level of corruption is very serious, such that $\phi_{0}$ has a very low value, most values of $\theta \geq \bar{\theta}$. In this case, the authorities would have no incentive to devote any efforts to fight corruption. In this case, setting a low inflation level through inflation targeting or appointing a Rogoff-type conservative central banker would not by themselves induce the government to devote more effort to fight corruption. Perhaps reforms to reduce corruption and to improve fiscal capacity should be taken before adopting a monetary regime aiming at a low level of inflation.

If the initial corruption is not too serious but moderate, such that $\theta<\bar{\theta}$ holds, then the authorities would have incentive on their own to devote efforts to reduce the corruption. Setting a low inflation level through inflation targeting (to induce corruption fighting) would not hurt, though it is probably not a corruption-fighting tool by itself.

\section{CONCLUDING REMARKS}

In this paper, we have examined the effects of corruption and fiscal policy on inflation and reexamined the desirability of several popular monetary regimes, 
including inflation targeting, a fixed exchange rate, a currency board arrangement, and a Rogoff-type conservative central banker.

The simple model of a monetary policy game, whereby corruption adversely affects the taxable revenue that the government can collect, has generated a number of interesting results for the literature on optimal monetary policy and for the literature on corruption. First, pegged exchange rate regime, currency board, or dollarization are often prescribed as means to increase the credibility of a government's resolve to maintain low inflation. Our analysis suggests that these monetary regimes may not be very credible themselves and can fail in countries where underlying corruption is serious. Second, an optimally chosen conservative central banker is generally preferable to a mechanical inflation target of 1-4 percent and to all exchange-rate-based monetary arrangements. The optimal degree of conservatism is inversely related to the level of corruption in the economy. Third, the notion that a low inflation target or a currency board can be used as an instrument to induce governments to fight corruption is questionable. These findings are important in the design of monetary policies for developing countries.

A number of further extensions can be made to the work done in this paper. For example, the government can be allowed to borrow in domestic bond market or international capital market. The interactions among corruption, debt, and monetary policies can be explored. These can be some of the important issues for future research. 


\section{References}

Acemoglu, Daron, Simon Johnson and James Robinson, 2002, "Reversal of Fortune: Geograghy and Institutions in the Making of the Modern World," Quarterly Journal of Economics, Vol. 117, pp. 1231-1294.

Acemoglu, Daron, James Robinson, Simon Johnson, 2001, "The Colonial Origins of Comparative Development: An Emperical Investigation," American Economic Review, Vol. 91, pp. 1369-1401.

Alesina, Alberto, and Guido Tabellini, 1987, "Rules and Discretion with Noncoordinated Monetary and Fiscal Policies," Economic Inquiry, Vol. 25, No. 4, pp. 619-30.

Backus, David, and John Driffill, 1985, "Inflation and Reputation," American Economic Review, pp. 530-538.

Bai, Chong-En, and Shang-Jin Wei, 2000, "Quality of Bureaucracy and Open-Economy Macro Policies,” NBER Working Paper No. 7766 (June).

Bardhan, Pranab, 1997, "Corruption and Development: A Review of Issues," Journal of Economic Literature, Vol. 35, pp. 1320-46.

Barro, Robert, 1986, "Reputation in a Model of Monetary Policy with Incomplete Information," Journal of Monetary Economics, Vol. 17, No. 1, pp. 3-20.

Barro, Robert, and David Gordon, 1983, "Rules, Discretion, and Reputation in a Model of Monetary Policy,” Journal of Monetary Economics, Vol. 12, No. 1, pp. 101-22.

Benigno, Pierpaolo, and Michael Woodford, 2003, "Optimal Moneau and Fiscal Policy: A Linear-Quadratic Approach," in M. Gertler and K. Rogoff, eds., NBER Macroeconomics Annual 2003, Vol. 18.

Berger, Helge, Jakobde de Haan, and Sylvester C.W. Eijffinger. 2001, "Central Bank Independence: An Update Theory and Evidence," Journal of Economic Survey, pp. 340 .

Bernanke, Ben, Thomas Laubach, Frederic S. Mishkin, and Adam S. Posen, 1999, Inflation Targeting: Lessons from the International Experience, Princeton University Press.

Calvo, Guillermo, 1978, "On the Time Consistency of Optimal Policy in a Monetary Economy," Econometrica, Vol. 46, pp. 1411-28.

Canzoneri, Matthew B., 1985, "Monetary Policy Games and the Role of Private Information," American Economic Review, Vol. 75, No. 5 (December), pp. 1056-70. 
Cukierman, Alex, 1992, Central Bank Strategy, Credibility and Independence. Cambridge: MIT Press.

Du, Julan, and Shang-Jin Wei, 2003, "Does Insider Trading Raise Stock Market Volatility?" NBER Working Paper 9541 (March) and forthcoming in Economic Journal. Available online at http://www.nber.org/papers/w9541.

Eichengreen, Barry, Paul Masson, Miguel Savastano, and Sunil Sharma, 1999, "Transition Strategies and Nominal Anchors on the Road to Greater Exchange-rate Flexibility," Essays in International Finance No. 213 (Princeton: Princeton University).

Fischer, Stanley, 1995, “Central-Bank Independence Revisited," American Economic Review, Vol. 85, No. 2, pp. 201-6.

Fischer, Stanley, 1982, "Seigniorage and the Case for a National Money," Journal of Political Economy, Vol. 90, No. 2, pp. 295-313.

Fisman, Raymond, and Shang-Jin Wei, 2001, "Tax Rates and Tax Evasion: Evidence from 'Missing Imports' in China," NBER Working Paper 8551 (October) and forthcoming, Journal of Political Economy. Available online at http://www.nber.org/papers/w8551.

Ghosh, Atish R., Anne-Marie Gulde, and Holger C. Wolf, 2000, "Currency Boards: More Than a Quick Fix?” Economic Policy: A European Forum, Vol. 90, No. 2, pp. 269 321.

Ghosh, Atish R., Anne-Marie Gulde, and Holger C. Wolf, 2003, Exchange Regimes: Choices and Consequences, MIT Press.

Huang, Haizhou, and Jorge Padilla, 2002, "Fiscal Policy and the Implementation of the Walsh Contract for Central Bankers" Annals of Economics and Finance, Vol. 3, pp. 27-42.

Kydland, Finn E., and Edward C. Prescott, 1977, "Rules Rather than Discretion: The Inconsistency of Optimal Plans," Journal of Political Economy, Vol. 85, No. 3, pp. 473-91.

Masson, Paul R., Miguel A. Savastano, and Sunil Sharma, 1997, "The Scope for Inflation Targeting in Developing Countries," IMF Working Paper 97/130 (Washington, DC.: International Monetary Fund).

Maskin, Eric, and John Moore, 1999, "Implementation and Renegotiation," Review of Economic Studies, Vol. 66, No. 1, pp. 39-54.

Mauro, Paolo, 1995, “Corruption and Growth," Quarterly Journal of Economics, Vol. 110, pp. 681-712. 
Moore, John, 1992, "Implementation, Contracts, and Renegotiation in Environments with Complete Information," in Advances in Economic Theory: Sixth World Congress, Vol. 1, pp. 182-282, ed. by Jean-Jacques Laffont (Cambridge: Cambridge University Press).

Moore, John, and Repullo, Rafael, 1988, "Subgame Perfect Implementation," Econometrica, Vol. 46, pp. 1192-220.

Moore, John, and Repullo, Rafael, 1990, "Nash Implementation: A Full Characterization," Econometrica, Vol. 58, pp. 1083-99.

Persson, Tosten, and Guido Tabellini, 1990, Macroeconomic Policy, Credibility and Politics. London: Harwood Publishers.

Rauch, James E., and Peter B. Evans, 2000, "Bureaucratic Structure and Bureaucratic Performance in Less Developed Countries," Journal of Public Economics, Vol. 75, No. 1. pp. 49-71.

Rogoff, Kenneth, 1985, “The Optimal Degree of Commitment to an Intermediate Monetary Target," Quarterly Journal of Economics, Vol. 100, No. 4, pp. 1169-90.

Rose-Ackerman, Susan, 1975, “The Economics of Corruption," Journal of Public Economics, Vol. 4, No. 2, pp. 187-203.

Shleifer, Andrei, and Robert Vishny, 1993, "Corruption," Quarterly Journal of Economics, Vol. 108, pp. 599-617.

Svensson, Lars, 1997, “Optimal Inflation Targets, 'Conservative' Central Banks, and Linear Inflation Contracts,” American Economic Review, Vol. 87, pp. 98-114.

Van Rijckeghem, Caroline, and Beatrice Weder, 2001, "Bureaucratic Corruption and the Rate of Temptation: Do Watges in the Civil Service Affect Corruption, and by How Much?" Journal of Development Economics, Vol. 65, No. 2, pp. 307-31.

Walsh, Carl, 1995, "Optimal Contracts for Central Bankers," American Economic Review, Vol. 85, No. 1, pp. 150-67.

Wei, Shang-Jin, 2000a. "How Taxing is Corruption on International Investors?" Review of Economics and Statistics, Vol. 82, No. 1, pp. 1-11.

Wei, Shang-Jin, 2000b. "Local Corruption and Global Capital Flows," Brookings Papers on Economic Activities, Vol. 2.

Wei, Shang-Jin, 2001. "Domestic Crony Capitalism and International Fickle Capital: Is There a Connection?" International Finance, Vol. 4, No. 1, pp. 15-45. 